\title{
LAST PLANNER CONTROL SYSTEM APPLIED TO A CHEMICAL PLANT CONSTRUCTION
}

\section{A. Nieto-Morote ${ }^{1}$, F. Ruz-Vila ${ }^{2}$}

\begin{abstract}
The main difference between the Last Planner production control system developed by Ballard and classical control systems is the way in which projects are controlled and planned. The Last Planner system focuses on controlling production units, workflows and the quality of the performed work. It also permits the identification of the causes for the non-completion of planned work and decision making in accordance with the project requirements so that actions are timely and productivity is increased.

The objective of this paper is to present the results obtained from implementing the Last Planner system in the construction department of a chemical company. In this department, an information flow problem was detected among its members, in which supervisors lacked knowledge about the work to be performed until the project had been perfectly designed. This problem often led to meant long delays in the projects. The results from Last Planner system implementation show that identifying the constraints of the planned work leads to an improvement in the percentage and quality of completed activities.
\end{abstract}

Keywords: project management, last planner, project performance

Please, cite this article in press as: Nieto-Morote, A , Ruz-Vila, F, Last planner control system applied to a chemical plant construction, Journal of Construction Engineering and Management, Vol. 138, No. 2, February 2012, pp. 287-293

DOI: 10.1061/(ASCE)CO.1943-7862.0000415.

(c) 2012 American Society of Civil Engineers.

\footnotetext{
${ }^{1}$ Professor at Universidad Politécnica de Cartagena, Project Engineering Department, C/ Dr Fleming , s/n, 30203 Cartagena, Spain. E-mail: ana.nieto@upct.es
} 


\section{INTRODUCTION}

Project time management, which includes the processes required to manage the timely completion of a project, has traditionally been focused on defining the project schedule in terms of what SHOULD be done. Activities are identified, timed and sequenced to lead to the achievement of the goals of the project without considering whether they CAN actually be accomplished in the defined time period. Human and material resources are assumed to be available when they are needed to guarantee the completion of the planned activities, but this is not always the case because the available resources are usually organized in accordance with the project schedule to minimize differences between the real progress and the schedule baseline.

With traditional project time management methodologies, projects are developed under variable and uncertain conditions. To avoid this problem, Koskela (1999) emphasized the need for a new control system based on the following principles:

1. Activities should not begin until all of the requirements for completion have been met.

2. The realization of activities must be measured and monitored.

3. The causes for non-realization of activities must be identified and eliminated.

4. Losses in productivity must be avoided, and other activities must be assigned when the initially assigned tasks cannot be completed.

5. A short-term program should be designed, which considers activities whose constraints have been eliminated.

The Last Planner System (LPS) developed by Ballard (2000) seeks to identify what activities CAN be DONE. In this way, a list of activities that can be done is defined so that a Weekly Work Plan (WWP) may be designed. When an activity is included in the WWP, the participants in the project commit to DO it.

As shown in FIG. 1, in the traditional approach to project scheduling, SHOULD points directly to "Executing the Plan". In the new approach, scheduling means selecting from what SHOULD be DONE to complete a project then deciding for given time frames what actually WILL be DONE.

\footnotetext{
2 Professor at Universidad Politécnica de Cartagena, Electric Engineering Department, C/ Dr Fleming , s/n, 30203 Cartagena, Spain. E-mail: paco.ruz@upct.es
} 


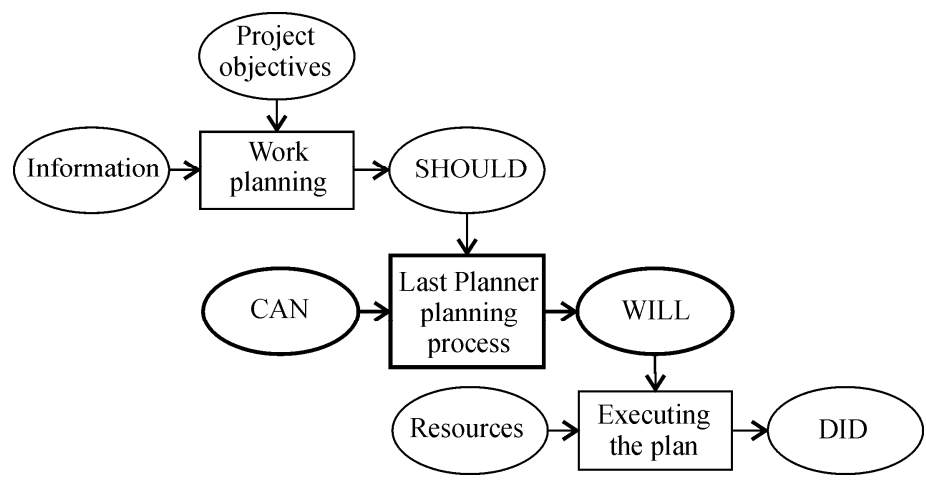

Figure 1.

\section{LAST PLANNER SYSTEM}

The LPS provides the planning and control tools necessary for managing projects even when they are complex and uncertain. Planning establishes project goals and a sequence of activities for achieving these goals; control causes activities to approximate the desired sequence, initiates re-planning when the established sequence is either no longer feasible or no longer desirable, and initiates learning when activities fail to conform to the plan. The definition of control used in current practices is much different. When construction projects are developed in dynamic environments, reliable planning cannot be performed in detail with a master schedule established at the beginning of the project. Therefore, the master schedule is not sufficient to decide what and how much work is to be done next. Consequently, LPS employs a three-level hierarchy of schedules, as shown in FIG. 2:

1. The master schedule is the overall project schedule and contains the major milestones only. The milestone dates are determined beginning with the project completion date and working backwards to the beginning of the project.

2. The look-ahead schedule represents an intermediate level of planning. This schedule contains the major activities that must be executed to complete the milestones at the times set in the master schedule. These activities are screened prior to entry in the look-ahead schedule to define the workable backlog. Screening essentially means that all of the constraints that could limit the completion of an activity (e.g., authorizations, resources, status of prerequisites work, etc.) are identified and that enough time remains prior to the scheduled start date of the activity to eliminate the constraints. This schedule typically looks ahead six to eight weeks. The exact duration of the look-ahead window depends on the time required to eliminate the constraints. Management 
continues to break activities into more detail and screen the resulting smaller activities throughout the look-ahead window until the activities become assignment-level tasks.

3. The sort-term schedule is an assignment-level schedule with a duration of one week. This schedule includes all assignments or work activities that are required to be started that week to comply with the completion dates in the look-ahead schedule. Work assignments must be ready to begin prior to their inclusion in the WWP, i.e., all constraints, including prerequisite work, must have been eliminated, and resources must be available and properly assigned to complete the task.

The reliability of the WWP is measured by Percent Plan Complete (PPC), which is defined as the percentage of those assignments on the weekly work plan that are completed that week. For those assignments that are planned but not completed, the root causes of the non-completion are determined and actions are taken to prevent them from recurring.

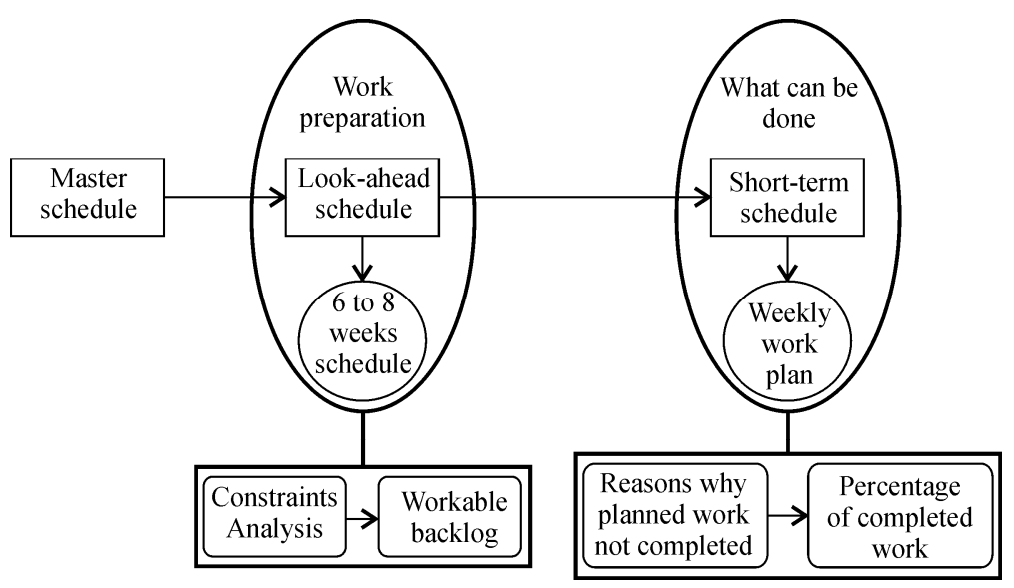

Figure 2.

In spite of the difficulties entailed in accepting new operational systems, this planning and control system has been implemented in numerous projects around the world and has led to important improvements in project performance, as shown in the following cases.

In 1994, Construction Concepts recommended a productivity improvement program on PARC, which was a refinery expansion project for Maraven S.A. (Venezuela). Ballard et al. (1997) proposed an improvement strategy based on the idea that planning reliability was the key to improved performance. The goal was to give only workable assignments to direct workers and to increase the predictability of the work flow for every organization. Difficulties were encountered in applying the strategy, for example, personnel were often not familiar with the concepts, and when they did understand them, they were not 
always willing to make commitments in an environment of pressure and blame. However, improvement was possible, and the project was completed on schedule and within its approved budget.

Another example is the case of Constructora Reynold, a civil engineering company from a small town in Sao Paulo State, which sought to optimize its operational performance by improving the quality of its products in relation to the market requirements and also by reducing its production costs to lower sale prices and stabilize their profit margin. Conte (1998) presents the results of applying a model of production management based on the concepts of Lean Construction in one of the company's projects, the construction of a library in the Campinas city. The perceived advancements were the following: the project adhered to the schedule, the average number of laborers was stabilized to seven, the evolution of the PPC showed rates close to 1.00, the purchase of materials and service contracting showed improved performance and the project remained within the budget.

Lean construction has suggested new strategies for managing uncertainties at the production level in a project environment. Alarcón et al. (2000) present the results of a real project where the changes introduced in the planning process led to remarkable improvements in the planning process and project performance. A computer project simulation was also used to extend the analysis of the project and to illustrate the impact of uncertainty on project productivity and how some planning strategies can be used to protect production from uncertainty.

Fiallo et al. (2002) present the results obtained from applying the LPS to a building construction project in Quito (Ecuador). Although the contractors found the new planning and control system difficult because they usually performed the work focusing on finishing the tasks, without taking into account that a poor planning generates the waste of resources, the LPS was confirmed to be an effective planning and work control tool. The analysis of the results demonstrated that when contractor had faith in the programmed work and had a better supplier management policy, then fewer deviations occurred.

Salem (2006) presents a study of a construction project of a general contractor in Ohio in which six lean construction techniques were tested, namely the LPS, increased visualization, first-run studies, huddle meeting, the five S's and fail-safe for quality. The benefits of the implementation were tangible; the project was under budget and three weeks ahead of schedule, and the subcontractors were more satisfied with their relationships with the general contractor.

Alarcón et al. (2008) present an extensive analysis of the empirical evidence available for assessing the impact of the implementation of Lean Construction practices in over one hundred construction projects. 
The analysis demonstrates the effectiveness of the proposed practices and their multiple benefits, such as, reliability of planning and improvements in PPC and performance.

\section{CASE STUDY}

In 1989, the American firm General Electric (GE) Plastics decided to construct a plant dedicated to manufacturing the plastic Cycoloy at Cartagena (Spain). In 1994, the compounding plant became operational with a production capacity of 40,000 metric tons per year.

The next investment of GE Plastics was the first polycarbonate plant to manufacture LEXAN (LX1), with a production capacity of 130,000 metric tons per year. When it was inaugurated in 1999 , it was converted in the first large plant to utilize Melt technology. Despite the challenge of building and stably operating a new plant with Melt technology, success was achieved. Due to the success of LX1, GE Plastics decided to construct a twin plant (LX2), which was inaugurated in 2005.

In November of 2003, a new investment of 350 million euros was confirmed. This latest investment, which comprises the fourth phase of the project, would consist of a plant for manufacturing the latest generation of engineering plastics known as ULTEM. In addition to the ULTEM plant, GE Plastics decided to establish a World R+D Center, which would not only guarantee technical assistance for the new plant but would also foster improvements in products and current production methods.

The construction of the new plant, whose inauguration was foreseen for the end of 2009, was initiated in 2005. Due to the purchase of GE's plastics division by the multinational SABIC Innovative Plastics and the economic crisis, the testing phase for each of the plant's units and its operating systems has only recently begun, and the plant is expected to become operational by mid-2010.

Despite the GE's experience in the construction of this type of plant, some problems presented during the construction of the ULTEM plant. The most significant problem that was detected is related to the supply of basic elements of work to the construction crew, such as information, materials, tools and equipment. The crew’s lack of information was especially troublesome.

Due to the company's organizational structure, the information passed from the Operational Department to the Contractor through the Project Leaders, Engineering Department and Construction Supervisors, successively. As a result of this arrangement, the construction supervisors, who are responsible for controlling the execution of the activities, and the contractors, who execute the activities, 
ignored the work that was assigned to them until the activities were specified in detail. Therefore, they did not have time to prepare appropriately for the work.

After analyzing the situation, a strategy of productivity improvement was deemed necessary and the Construction Leaders suggested applying the LPS to the supervision tasks. To analyze the benefits of the application of the LPS, a small scale preliminary study was implemented. Only six supervisors from different engineering disciplines (civil, mechanical, electrical, electronics, process control \& instrumentation and structural), who worked on 136 subprojects of the ULTEM plant construction project, participated in the pilot experience.

\section{LAST PLANNER SYSTEM IMPLEMENTATION}

The main focuses of the application of the LPS in this enterprise were the following:

- to decrease the uncertainty related to projects and the executive planning of the construction,

- to guarantee the complete control of information and its adequate distribution,

- to create conditions for the persons involved to be compromised with goals, and

- to allow actions of repositioning to be planned and executed by construction personnel.

To achieve these objectives, a committee was formed, which was integrated not only with planning managers but also with project leaders and the six project supervisors, who have knowledge of the execution problems in detail.

The master schedule was revised by the committee. Based on this schedule, the look-ahead schedule was designed to take into account that given the nature of the project and the response time for the acquisition of information, materials, labor, machinery, etc. Thus, the duration of the look-ahead window was chosen to be 6 weeks.

During each of these weeks, each supervisor provided a list of the constraints preventing the execution the planned activities of each subproject, with the objective of reducing or eliminating the identified constraints to enable the performance of the activities. Those activities whose constraints had been eliminated were included in the WWP.

In the weekly planning meetings, each supervisor reviewed his completion of the look-ahead planning and the WWP activities, and measured the plan reliability with the PPC. If any planned activities for that week had not been completed, the supervisor identified the reasons for not completing the task. 
The results of these meetings were recorded in accumulation graphs and constraints analysis documents, which, together with the percentage of activities completed each week, allowed the progress in the project performance to be tracked. The process details changed each week as it was adapted to the varying requirements. Because the process was open, the following particularities were taken into account each week:

1. For the first week, a long list of constraints was defined. Due to the great number of constraints to consider, the committee decided to focus the project leader's efforts on the key points.

2. In the second week, another long list of constraints was obtained. Those constraints were classified into two groups:

a. Actions. This group was composed of constraints on which project leaders could act. These actions could include, for example, tasks of coordination with the Operations Department, such as the connection of pipelines under pressure by means of welding (HOT-TAP), the placement of a lockout/tagout device on an energy isolating device (LOTO), the connection of a device with another (TIE-INS), tasks of coordination between the Engineering Department and the supervisor or between materials suppliers and the supervisor, or tasks of coordination with maintenance and/or contractors.

b. No actions: This group was composed of constraints on which project leaders will not act because they are on standby (on hold) they have already acted on them (work in progress).

3. In the third week, the constraints were classified in accordance with the above criteria. The project leaders concentrated their attention to the constraints that were classified as Actions to determine how and when they will be eliminated. In this way, the schedule was modified to take into account the date in which the activities could once the constraints had been eliminated.

4. For the fourth, fifth and sixth weeks, the constraints classified as Actions in the previous weeks that were not initiated were again analyzed, together with the constraints corresponding to those weeks.

\section{RESULTS}

As explained before, a planning meeting was held every week to analyze the project execution. This analysis consisted of identifying the constraints on the activities that prevented their completion and proposing solutions to eliminate them, in addition to defining the percentage of completed activities with regard to the planned activities and identifying the reasons why certain planned activities were not 
completed. In this way, information was gathered that could assist in solving future problems in the performance and execution of the activities planned for each week.

\section{Constraints analysis}

As an example, the constraint analyses conducted over the six weeks of the pilot project corresponding to the instrumentation supervisor are shown.

The list of constraints identified by the instrumentation supervisor during the first week of application of the LPS is shown in Table 1.

Table 1. List of constraints of the first week

\begin{tabular}{|l|l|l|}
\hline $\begin{array}{l}\text { Subproject } \\
\text { number }\end{array}$ & Activity & Constraints \\
\hline 6806002 & LX1 Cooling water pump shutdown (FTs) & $\begin{array}{l}\text { Pending to complete electric works and } \\
\text { confirm by Operations Department. }\end{array}$ \\
\hline 6806003 & Install new orifice plate for FE6830208 & Lack of design, materials and contractors \\
\hline 6906001 & CO analyzer for caloric HO furnace & Pending to Operations Department \\
\hline 8106001 & Cold box purge to H81200 & Lack of contractors and materials \\
\hline 8806001 & LX2 Cooling water pump shutdown & Pending to Operations Department \\
\hline 6306002 & $\begin{array}{l}\text { Install new FQI in demineralised water } \\
\text { lances }\end{array}$ & Lack of materials \\
\hline 6306003 & DPC addition pump reliability & Pending to overhaul \\
\hline 6605006 & Refrigeration system & Lack of design \\
\hline 6605003 & Change of valves IRIS & Pending to Operations Department \\
\hline 6606004 & New sump pump N-66724 & Pending to assemble valve FV-82206-95. \\
\hline 6105007 & Change CPUs of PLC TMR POX & Pending to overhaul \\
\hline \hline
\end{tabular}

Due to the great number of the identified constraints that project leaders received, it was decided that during the following weeks constraints would be classified into Actions and No actions, and project leaders would only be given constraints classified as Actions. In this way, project leaders would concentrate their efforts on those activities on which action could be taken. Table 2 shows the identified constraints for the second week, which were classified into Actions and No actions.

The list of the identified constraints for the third week was shorter than the previous lists, as shown Table 3. Once the corresponding project leader was informed about the activity constraint and this constraint was analyzed, activities were executed during the overhaul of LX2 plant, and the constraints were eliminated in the following weeks.

The identified constraints and results of the analyses of activities classified as Action that were compiled over the following weeks of the application of the LPS are shown in Table 3. 
Table 2. List of constraints and classification for the second week

\begin{tabular}{|c|c|c|c|}
\hline $\begin{array}{l}\text { Subproject } \\
\text { number }\end{array}$ & Activity & Constraint & Classification \\
\hline 6806002 & $\begin{array}{l}\text { LX1 Cooling water pump } \\
\text { shutdown (FTs) }\end{array}$ & $\begin{array}{l}\text { Pending to complete electric works } \\
\text { and confirm by Operations } \\
\text { Department. }\end{array}$ & $\begin{array}{l}\text { Action: Coordination with } \\
\text { Operations Department. }\end{array}$ \\
\hline 6806003 & $\begin{array}{l}\text { Install new orifice plate } \\
\text { for FE6830208 }\end{array}$ & Pending to Operations Department & No action: On hold. \\
\hline 6906001 & $\begin{array}{l}\text { CO analyzer for caloric } \\
\text { HO furnace }\end{array}$ & Lack of materials & $\begin{array}{l}\text { No action: Work in } \\
\text { progress }\end{array}$ \\
\hline 8106001 & $\begin{array}{l}\text { Cold box purge to } \\
\text { H81200 }\end{array}$ & Pending to Operations Department & $\begin{array}{l}\text { Action: Coordination with } \\
\text { Operations Department } \\
\text { (LOTO). }\end{array}$ \\
\hline 8806001 & $\begin{array}{l}\text { LX2 Cooling water pump } \\
\text { shutdown }\end{array}$ & Lack of materials. & $\begin{array}{l}\text { No action: Work in } \\
\text { progress }\end{array}$ \\
\hline 6306002 & $\begin{array}{l}\text { Install new FQI in } \\
\text { demineralized water } \\
\text { lances }\end{array}$ & Pending to overhaul & No action: On hold. \\
\hline 6306003 & $\begin{array}{l}\text { DPC addition pump } \\
\text { reliability }\end{array}$ & Lack of design. & $\begin{array}{l}\text { No action: Work in } \\
\text { progress }\end{array}$ \\
\hline 6605006 & Refrigeration system & Pending to Operations Department & No action: On hold. \\
\hline 6605003 & Change of valves IRIS & Pending to Operations Department & $\begin{array}{l}\text { Action: Coordination with } \\
\text { Operations Department. }\end{array}$ \\
\hline 6606004 & $\begin{array}{l}\text { New sump pump N- } \\
66724\end{array}$ & $\begin{array}{l}\text { Pending to assemble valve FV-82206- } \\
95 .\end{array}$ & No action: On hold. \\
\hline 6105007 & $\begin{array}{l}\text { Change CPUs of PLC } \\
\text { TMR POX }\end{array}$ & Pending to overhaul & No action: On hold. \\
\hline
\end{tabular}

Table 3. List of constraints and classification for the third, fourth, fifth and sixth week

\begin{tabular}{|c|c|c|c|}
\hline $\begin{array}{l}\text { Sub-project } \\
\text { Number }\end{array}$ & Activity & Constraint & Classification \\
\hline \multicolumn{4}{|c|}{ Third week } \\
\hline 6806002 & $\begin{array}{l}\text { LX1 Cooling water pump } \\
\text { shutdown (FTs) }\end{array}$ & $\begin{array}{l}\text { Pending to complete electric works and } \\
\text { confirm by Operations Department }\end{array}$ & No Action: On hold \\
\hline \multicolumn{4}{|c|}{ Fourth week } \\
\hline 8205010 & $\begin{array}{l}\text { Signal from compressors } \\
\text { operation to DCS }\end{array}$ & Lack of protection relays K-85340A/B & $\begin{array}{l}\text { Action: Coordination with } \\
\text { Operations Department. }\end{array}$ \\
\hline \multicolumn{4}{|c|}{ Fifth week } \\
\hline 8205010 & $\begin{array}{l}\text { Signal from compressors } \\
\text { operation to DCS }\end{array}$ & Lack of protection relays K-85340A/B & $\begin{array}{l}\text { Action: Coordination with } \\
\text { Operations Department. }\end{array}$ \\
\hline 6805001 & $\begin{array}{l}\text { Blackwash filtration } \\
\text { system for effluent line }\end{array}$ & Lack of design & $\begin{array}{l}\text { Action: Coordination with } \\
\text { Operations Department. }\end{array}$ \\
\hline 8305003 & Change ISOLOCKS & Lack of materials & No action: Work in progress \\
\hline 7006027 & $\begin{array}{l}\text { Isolation of V210 \&V350 } \\
\text { from MS during cleaning }\end{array}$ & Repair pumps & $\begin{array}{l}\text { Action: Coordination with } \\
\text { Operations Department. }\end{array}$ \\
\hline \multicolumn{4}{|c|}{ Sixth week } \\
\hline 8205010 & $\begin{array}{l}\text { Signal from compressors } \\
\text { operation to DCS }\end{array}$ & Lack of protection relays K-85340A/B & $\begin{array}{l}\text { Action: Coordination with } \\
\text { Operations Department. }\end{array}$ \\
\hline 7006027 & $\begin{array}{l}\text { Isolation of V210 \&V350 } \\
\text { from MS during cleaning }\end{array}$ & Lack of design. & $\begin{array}{l}\text { Action: Coordination with } \\
\text { Operations Department. }\end{array}$ \\
\hline 8205021 & Cyclon washing & Lack of T3 of signs. & $\begin{array}{l}\text { Action: Coordination with } \\
\text { Operations Department. }\end{array}$ \\
\hline 7005017 & $\begin{array}{l}\text { Polymerizer unit for } \\
\text { laboratory }\end{array}$ & Lack of materials. & No action: Work in progress \\
\hline 7000616 & Chute side feeder & Pending to Operations Department & $\begin{array}{l}\text { Action: Coordination with } \\
\text { Operations Department. }\end{array}$ \\
\hline
\end{tabular}




\section{Measurement of weekly work plan reliability}

The principal measure of the plan reliability is the percentage of the plan that is completed, i.e., the percentage of planned activities that are completed. FIG. 3 shows the weekly evolution of the PPC corresponding to the six construction supervisors who participated in the study.

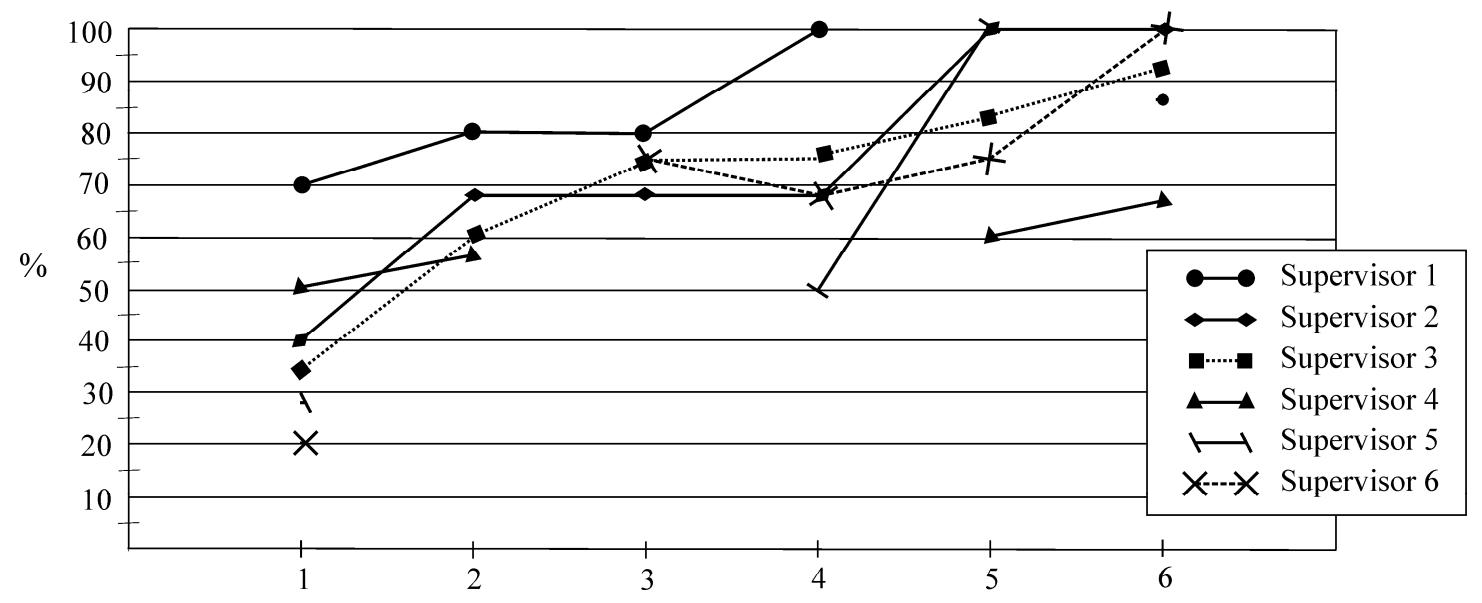

Weeks

Figure 3.

The discontinuities of some lines are due to the fact that the supervisors did not have any activities assigned in the WWP for the corresponding weeks.

As an example, the number of planned activities that were completed and not completed each week, i.e., the weekly PPC, as well as the reasons for the non-completion of certain activities corresponding to supervisor 3 are shown in Table 4 .

Table 4. Percentage of activities not completed and reasons why they have not been completed corresponding to supervisor 3.

\begin{tabular}{|c|c|c|l|c|}
\hline \hline Week & $\begin{array}{c}\text { Activities } \\
\text { completed }\end{array}$ & $\begin{array}{c}\text { Activities not } \\
\text { completed }\end{array}$ & \multicolumn{1}{|c|}{$\begin{array}{c}\text { Reasons why the activities have not been } \\
\text { completed }\end{array}$} & \multirow{2}{*}{ PPC } \\
\hline \hline \multirow{2}{*}{$1^{\text {st }}$} & 2 & 2 & Lack of design. & $40 \%$ \\
\cline { 3 - 5 } & 2 & 1 & Coordination works from operations department. & \multirow{2}{*}{$67 \%$} \\
\hline $2^{\text {nd }}$ & 2 & 1 & Coordination works from operations department. & $67 \%$ \\
\hline $3^{\text {rd }}$ & 2 & 1 & Coordination works from operations department. & $67 \%$ \\
\hline $4^{\text {th }}$ & 3 & 0 & - & $100 \%$ \\
\hline $5^{\text {th }}$ & 4 & 0 & - & $100 \%$ \\
\hline $6^{\text {th }}$ & & & & \\
\hline
\end{tabular}




\section{Reasons why the planned activities are not completed}

The evolution of the PPC reveals a weekly reduction in the number of the planned activities that are not executed.

In the first week of the application of the LPS, the supervisors did not have detailed information about the activities assigned to them, which meant that some of the planned work could not be executed. The reasons why planned activities were not completed during this first week are shown in the FIG. 4.

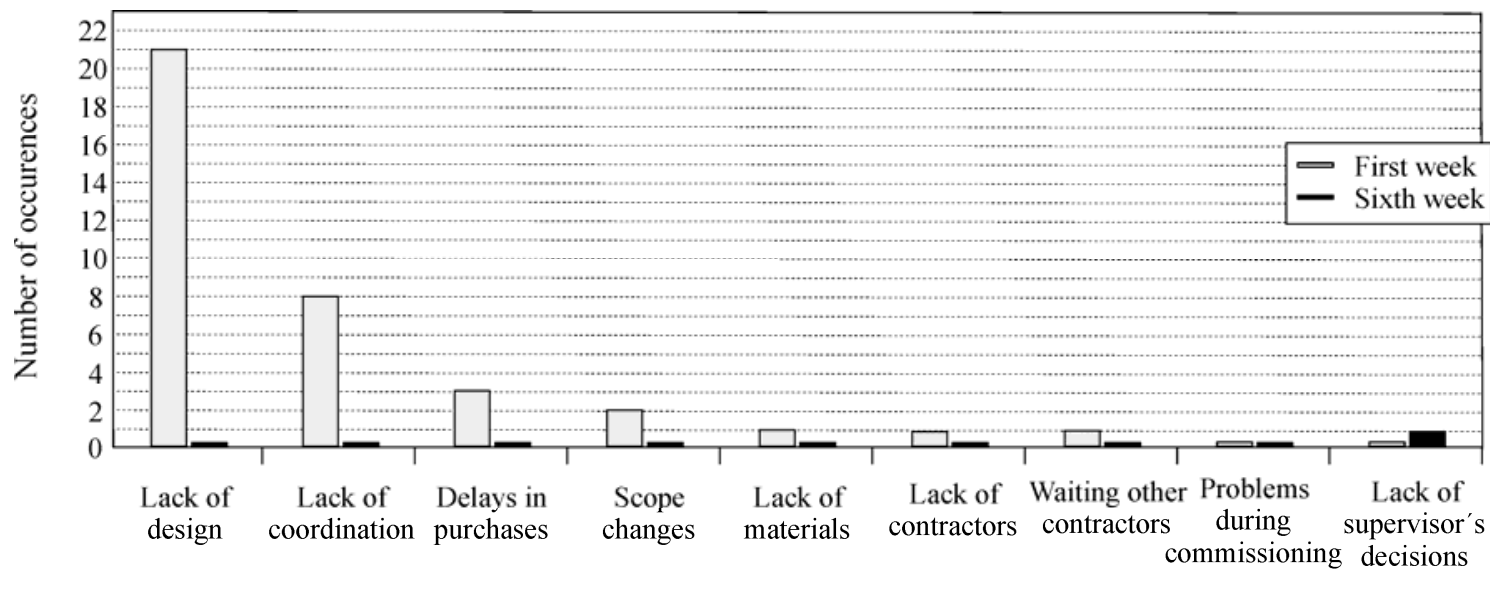

Reasons

Figure 4.

During each week, the supervisors gained knowledge about their activities, which led to the execution of an increasing number of planned activities. This effect is reflected in FIG. 4, where a significant decrease in the causes for non-completion of the planned activities is shown. Additionally, FIG. 5 shows the execution failures, planning failures and the percentage of activities completed in each week.

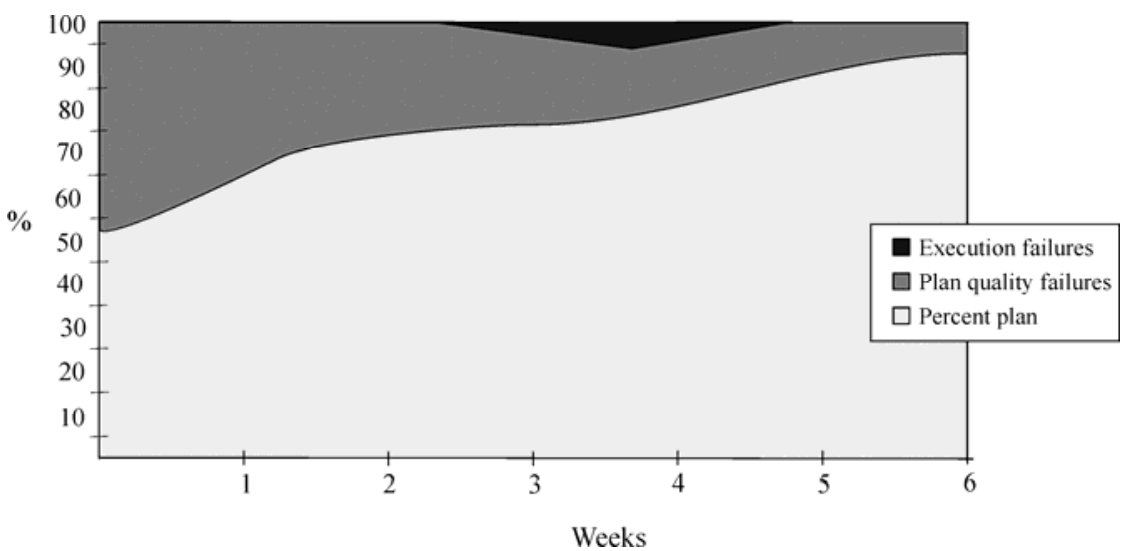

Figure 5. 


\section{Constraints analysis: actions and results}

For each week, a list of constraints was obtained, and, after the second week, the constraints were classified as Actions or No actions. The project leaders concentrated their efforts on the activities classified as Actions, so they could determine a date for eliminating the constraints limiting the execution of a certain activity. The results and actions accumulated during the application of the LPS and the results of the final week are shown in FIG. 6.

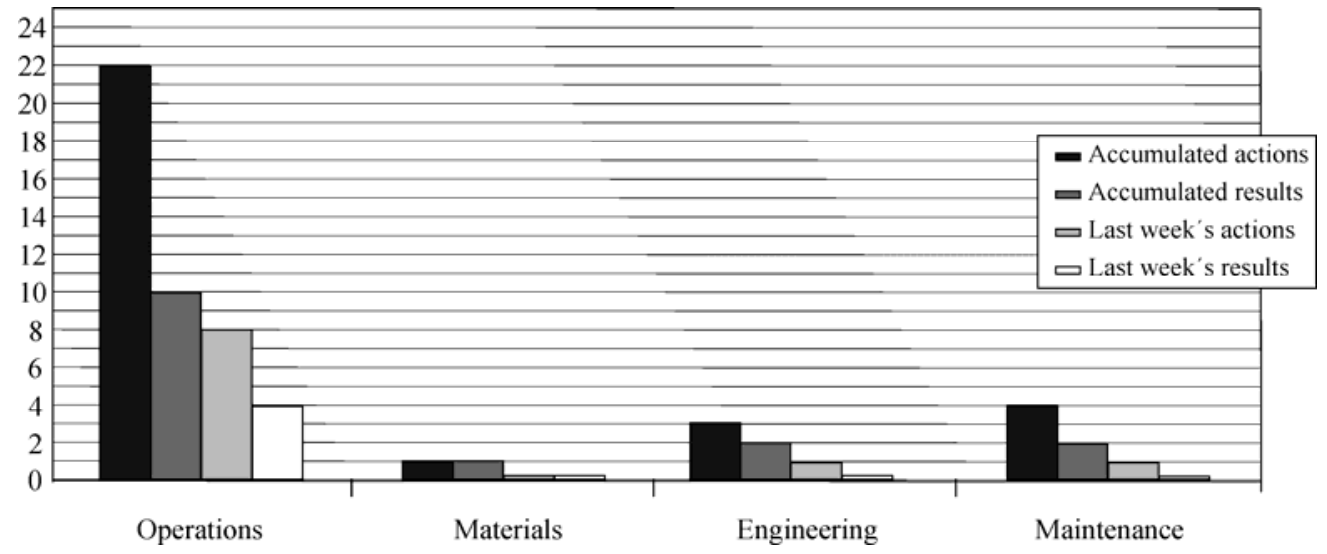

Figure 6.

The greatest number of constraints corresponds to the Coordination with Operations Department category. A detailed study of this category is presented in FIG. 7.

\begin{tabular}{|c|c|c|c|c|c|c|}
\hline & & & & & & \\
\hline & DMC; LX-2 & & & & & \\
\hline & DMC; LX-1 & & & & & \\
\hline & DPC; LX-2 & & & & & \\
\hline & DPC; LX-1 & & & & & \\
\hline & K-85340A|B B & PA LX-2 & & & & \\
\hline & N-85447-B BPA & LXX-2 & & & & \\
\hline & N-63710-B DP & c; LX-1 & & & & \\
\hline & Reactors A C & & & & & \\
\hline & Tasks 3 weeks & & & & & \\
\hline & Tasks 2weeks & & & & & \\
\hline & $\mathrm{CO} ; \mathrm{LX}-2$ & & & & LX PC; LX-2 & \\
\hline & Utilities; LX-2 & & & CO; LX-1 & Utilities; LX-1 & \\
\hline & DMC; LX-1 & & DPC; LX-1 & Utilities; LX-1 & Pilot plant & LX PC; LX-2 \\
\hline
\end{tabular}

Figure 7. 
Of all the activities involved in the study, 13 activities had constraints related to process connections. This means that there are significant faults in the design phases of the various projects because what will have to be done or when it will have to be done is not indicated. This problem could be eliminated by defining how and when the activity should be completed during design phases.

\section{CONCLUSIONS}

The main objective of this study was to analyze the effects of implementing the LPS on the performance of a construction project, namely the construction of a chemical plant for GE Plastics.

Due to the company's organizational structure, there was a problem with the information flow. Consequently, construction supervisors and contractors ignored the work that was assigned to them. Therefore, they did not have time to prepare appropriately the work. A pilot experience, with only six construction supervisor was developed to assess the possible positive effects of the LPS implementation on the project performance.

Starting from the body of knowledge of the LPS, its basic principles were adapted to the particular characteristics of this project. The two most important difficulties that were presented were the following:

- modifying the operational procedures that were widely accepted by the construction crew and

- the purchase process GE's plant at Cartagena by the multinational SABIC Innovative Plastics, which generated great uncertainty in the project performance. The change of ownership did not permit the continuation of the Last Planner System implementation despite the obtained success in the application

By analyzing the obtained results, the following conclusions were made:

1. The percentage of activities completed is improved when the look-ahead schedule and the weekly work plan processes are reapplied. The more the processes are reapplied, the higher is the percentage of completed activities.

2. All of the project leaders, supervisors and contractors should have a proactive role in controlling the development of the project. They should all analyze the reasons why work has not been completed and identify the basic prerequisites and/or the tools needed to complete an activity. By taking a 
more active role, they will have more information about their projects and feel more involved and motivated.

3. The number of reasons for not completing the planned work can be reduced considerably each week.

4. Of the 158 constraints that were identified, 41 constraints were classified as Actions and 15 were eliminated.

5. The analysis of the constraints allows the nature of the most important causes that limit the way in which an activity is done to be detected, so efforts may be concentrated to resolve these causes. As an example, more constraints are classified as Actions that are related to coordination with the Operations Department as the weeks progress.

All of these results affirm that the Last Planner System is an effective tool for improving project performance.

\section{REFERENCES}

Alarcón LF., Ashley DB., and Cruz J., (2000). “The impact of planning strategies on project performance: Learning from real and model project”. Proceedings $8^{\text {th }}$ Conference of the International Group for Lean construction. University of Berkeley. California.

Alarcón LF., Diethelm S., Rojo O., Calderón R., (2008). “Assessing the impacts of implementing lean construction”. Revista Ingeniería de Construcción, 23 (l), 26-33.

Ballard, H. G., Casten, M., and Howell, G. (1997). "Parc: A case study” Proceedings $4^{\text {th }}$ annual conference of international group for Lean construction. Birmingham.

Ballard, H. G., (2000) "The Last Planner System of production control” PhD submitted to Faculty of Engineering of the University of Birmingham.

Choo, H., Tommelein, I., Ballard,G.. Zabelle, T. (1999). "Workplan: Constraint-based database for work package scheduling” J. Construction. Engineering. and Management., ASCE, 125(3), 151-160.

Conte, A. (1998). "Last Planner, Lookahead, PPC: a driver to the site operations" Proceedings $5^{\text {th }}$ Conference of the International Group for Lean construction.

Fiallo M., Revelo V. (2003). “Applying the Last Planner control system to a construction project: a case study in Quito, Ecuador. Proceedings $10^{\text {th }}$ Conference of the International Group for Lean construction, Gramado, Brasil. 
Koskela, L. (1999). “Management of Production in Construction: A Theoretical View”. Proceedings of the 7th Annual Conference of the International Group for Lean Construction, University of California,Berkeley, 241-252.

Salem, O., Solomon, J., Genaidy, A.; Minkarah, I., (2006). “Lean Construction: From Theory to Implementation.” Journal of management in engineering, 22 (4), 168-175. 